\title{
Evaluation of Public Awareness about Orthodontic Treatments in Two Cities of Iran
}

Rafighi Ali ${ }^{1}$, Moslemzadeh Hossein ${ }^{1}$, Foroughi M Saeid ${ }^{1 *}$, Soltani Rahim ${ }^{1}$, Shadi Afshin ${ }^{1}$

1. Faculty of Dentistry, Tabriz University of Medical Science, Tabriz, Iran

\begin{abstract}
Objective: Most orthodontic patients are children or adolescents. In recent years, orthodontic treatment in adults, also has gained social and professional acceptance. Adults have undoubtable effect on overall treatment demand. Parents are the most powerful single factor in children motivation for treatment. Therefore, parents and other members of the society are expected to have proper knowledge about orthodontic problems. The purpose of this study was to determine and compare public awareness about orthodontic treatment in two cities of Iran.

Materials and Methods: A questionnaire consisting of 17 questions, including general information, suitable age, and costs of orthodontic treatment, was given to 384 subjects. The questionnaire was given to healthcare centers in different districts of both cities in order to justify a homogeneous study sample. The public awareness in two cities was analyzed and compared with independent t-test.

Results: There was no significant difference between the two cities in general information and their opinion about the costs of the orthodontic treatment. The difference in public awareness about the proper age for orthodontic treatment was statistically significant between the two cities $(p=0.002)$.

Conclusion: General awareness of people about orthodontic treatment in both cities was not adequate, and in the two cities, high costs of orthodontic treatment were the main problems causing treatment demand reduction. Knowledge of people in Tabriz about proper age of orthodontic treatment was higher.
\end{abstract}

Key words: Health Care Costs; Health Knowledge; Health Service Needs and Demands; Orthodontics

\section{Introduction}

Tooth misalignment and malocclusion may cause social and psychological impact due to different facial appearance, and may give rise to some oral function problems such as difficulties in jaw movements, tempromandibular joint disorders, problems with mastication, swallowing or speech and greater susceptibility to trauma, periodontal disease or caries $(6,9)$.

Orthodontists and orthodontic science with clinical procedures can alter and hopefully improve a patient's facial appearance and

\section{Corresponding author:}

Foroughi M, Saeid

Faculty of Dentistry, Tabriz University of Medical Science, Tabriz, Iran

Receive date: 2014-08-16| Accept date: 2014-08-29| Publish date: 2014-09-19

DOI: 10.7575/aiac.abcmed.15.03.01.09

\section{A. I}


psycho-social status. Orthodontic treatment can be useful in treatment and improvement of developmental, functional and oral health problems $(6,9)$.

Demand for orthodontic treatment is influenced by various factors such as malocclusion prevalence and severity, sex, socio-economic status, ethnic origin, availability and funding of orthodontic services. $(11,13)$ For example both the perceived need and demand vary with social and cultural conditions. More children in urban areas are thought (by parents and peers) to demand treatment than children in rural areas. Family income is a major determinant of how many children receive treatment (14). Also some studies showed that different cultural and socioeconomic conditions do not necessarily resulted in significant differences in awareness about orthodontics and subsequent treatment demand (10) .

On the other hand the tests of psychological reaction of individuals to various dental conditions show that cultural differences are smaller than what might have been anticipated (2).

Most orthodontic patients are children or adolescents. Furthermore, orthodontic treatment in adults has gained social and professional acceptance in recent years. (4) Parents are found to have noticed occlusal defects in their children almost as frequently as dentists, and are the most powerful single factor in the motivation for treatment. (5) Oral health knowledge and similarly awareness about orthodontic treatment are considered to be an essential prerequisite for health related behavior and orthodontic treatment demand. Studies have shown that there is an association between increased knowledge and better oral health (3).

The purpose of this study was to evaluate and compare public awareness about orthodontic treatment in two cities (Tabriz \& Bukan) in Iran.

\section{Materials and Methods}

Two cities (Tabriz and Bukan) were selected as survey sites. The selection was based on apparent differences in cultural, social, economic, population and availability of orthodontic services such as presence of orthodontists and university with associated dental school and postgraduate department of orthodontics.

In two cities, some healthcare centers were chosen according to type of services dispersion and city texture in order to justify a homogeneous sample, that is, some centers were selected and in those centers some samples were selected to ask take part in this survey. Ultimately, a total of 384 participants (204 in Tabriz, 180 in Bukan) were selected.

A questionnaire consisting of 17 questions in 3 sections, including general information, proper age, and costs of orthodontic treatment was prepared and the participants were given 15 minutes to fill it, which was a short time to gather information from other sources.

Face and content validity of the questionnaire, confirmed by the specialists, was based on the articles especially the article by Rafighi et al. (10) on social awareness of the orthodontic treatment. Each wrong answer was given 0 point and 1 point was given for each correct answer. Mean scores about general information, proper age, and costs of treatment were assessed separately by descriptive statistical analysis. KolmogorovSmirnov test was used to check normality of data distribution. Independent t-test was used to compare the awareness between the two cities.

\section{Results}

The questionnaire had proper reliability according to the Cronbach's Alpha coefficient 
(0.62). In Tabriz 188, 197 and 148 participants out of 204 answered all the questions of general information, proper age and treatment costs, respectively: 155, 155, and 144 out of 180 did the same in Bukan.

Mean scores for general information were $51.84 \pm 22.84$ in Tabriz and 48.49 \pm 25.41 in Bukan, with no statistically significant difference $(p=0.173)$.

Mean scores for knowledge about proper age of orthodontic treatment were 51.38 and
41.66 in Tabriz and Bukan respectively, with statistically significant difference $(p=0.002)$.

Of all the subjects, $64.3 \%$ stated that orthodontic treatment is too expensive. However, $13.4 \%$ and $1.6 \%$ of participants thought that the costs are reasonable and low, respectively.

The answers to some important parts of questionnaire are summarized in Table 1.

Table 1: Percent (\%) of some answers to some important parts of questionnaire

\begin{tabular}{|c|c|c|c|}
\hline Provider's answer & Tabriz & Bukan & Mean \\
\hline Have heard about orthodontics & 82.9 & 69.3 & 76.6 \\
\hline Knew that orthodontics is aligning teeth by braces & 88.9 & 85.6 & 87.4 \\
\hline Orthodontics is only for esthetical purposes & 34.3 & 36.5 & 35.6 \\
\hline Teeth could be moved in the gum & 57.3 & 51.3 & 55.5 \\
\hline $\begin{array}{l}\text { Slow movement of teeth in the bone has no side effect on } \\
\text { teeth }\end{array}$ & 42 & 38 & 40.8 \\
\hline $\begin{array}{l}\text { Backward and forward position of the jaws cannot be treated } \\
\text { at any age by orthodontic treatment }\end{array}$ & 30.2 & 37.1 & 33.9 \\
\hline Treatment duration is about 1 to 2 years & 51.2 & 48.9 & 50.1 \\
\hline We can extract permanent teeth for orthodontic purposes & 48.3 & 22.6 & 36.4 \\
\hline Orthodontic treatment can be rendered at any age & 26 & 32.1 & 29.3 \\
\hline $\begin{array}{l}\text { Age is important factor in beginning and duration of } \\
\text { orthodontic treatment }\end{array}$ & 56 & 64 & 59.9 \\
\hline Orthodontic treatment should begin in young ages & 20.1 & 32.6 & 25.9 \\
\hline After 20 years old tooth movement is not possible & 22 & 15 & 18.8 \\
\hline Orthodontic treatment is expensive & 72 & 54 & 64.3 \\
\hline Had a relative under orthodontic treatment & 64 & 32 & 48 \\
\hline $\begin{array}{l}\text { Would have orthodontic treatment if needed without } \\
\text { considering its costs }\end{array}$ & 28.2 & 29 & 29.1 \\
\hline $\begin{array}{l}\text { Having braces in mouth is the major drawback of orthodontic } \\
\text { treatment }\end{array}$ & 23 & 31 & 28 \\
\hline High cost is the major drawback of orthodontic treatment & 49 & 45 & 48.9 \\
\hline
\end{tabular}




\section{DISCUSSION}

The purpose of this study was to determine the public awareness about orthodontic treatment in Tabriz and Bukan. A questionnaire was given to 384 participants in both cities to gather required information.

A little difference existed between two cities in general information, considering answers to each question, but the difference was not statistically significant.

A large percent of participants in both cities (76.6\%) had heard about orthodontics, which was higher in Tabriz.

Attention and gravity to the cosmetic aspect of orthodontic treatment in Tabriz was higher, while in Bukan, therapeutic aspect was more important.

Attractiveness and beautifulness may have greater degree of importance in different economic status. A major part of the participants in Tabriz had more correct answers to the possibility of tooth movement in the bone. Tabriz's participants observed more relative and family members under orthodontic treatment (64\% in Tabriz, 32\% in Bukan) and this factor may cause differences in understanding of tooth movement possibility.

In general, awareness and knowledge about orthodontic treatment adverse effects was low. Similarly, Pratelli et al. (8) concluded that knowledge of parents about orthodontic implications is not sufficient.

Thirty percent of all participants had correct answers about possibility of jaw movement by orthodontic treatment. This may be attributed to this believe that orthodontics is only tooth movement and not jaw movement.

Availability of orthodontic services and presence of dentistry faculty in Tabriz may be a factor for higher awareness in Tabriz about possibility of permanent tooth extraction during orthodontic treatments.

There was statistically significant difference in awareness about proper age of orthodontic treatments in two cities and people of Tabriz had higher awareness. Sixty percent of subjects believed that age is an important factor in orthodontic treatment, although 30.9\% of participates did not know about proper age of treatment beginning; in general, awareness was inadequate.

In both cities, media do not provide enough information about orthodontics, despite other differences such as cultural, societal, economic, population and availability of orthodontic services. Lack of information in media may be contributed to the lack of knowledge among people.

The results of this study were partially similar to the study performed by Rafighi et al. which also concluded that differences in socioeconomic conditions and availability of orthodontic services cause no differences in general information about orthodontics, proper age of treatment, and costs of treatment. (10) Pratelli et al. concluded that parents who desire orthodontic treatment for themselves, or have had former orthodontic treatment are more likely to perceive a need for it in their children (8).

Importance of an orthodontic information package was emphasized by Anderson et al. (1) Oshagh et al. (7) who showed that parents' awareness of children's orthodontic problems can be increased by means of information leaflets.

Main problem causing reduction in orthodontic treatment demand in both cities was costs of treatment. In addition to the costs, limitation of time was the other factor in making decision to carry out orthodontic treatment. 
Maybe if people had knowledge about the installment of orthodontic treatment costs, or if the insurance companies paid some part of it, the cost would no longer be the greatest factor precluding treatment. Engagement of insurance companies could play the role of information media as well.

We recommend that studies be carried out on the influence of any type of information media on orthodontic treatment awareness to find the appropriate methods of informing people of the subject.

\section{Conclusion}

There were no differences in general information and costs of orthodontic treatment in both cities. Maybe lack of information by any type of media contributed to inadequate awareness about orthodontics in both cities. Knowledge about proper age of orthodontic treatments was higher in Tabriz. Availability of orthodontic services such as specialists and presence of dentistry faculty may contribute to this difference.

\section{References}

1. Abdullah MA. Surface detail, compressive strength, and dimensional accuracy of gypsum casts after repeated immersion in hypochlorite solution. J Prosthet Dent.2006;95:462-8.

2. Stern MA,Johnson GH,Toolson LB.An evaluation of dental stones after repeated exposure to spray disinfectants.Part I:Abrasion and compressive strength.The journal of prosthetic dentistry.1991;65:713-8.

3. Egusa H, Watamoto T, Abe K, Kobayashi M, Kaneda Y, Ashida S, et al. An analysis of the persistent presence of opportunistic pathogens on patient-derived dental impressions and gypsum casts. The International journal of prosthodontics.2008;21:62.

4. Kumar RN, Reddy SM, Karthigeyan S, Punithavathy R, Karthik KS, Manikandan R. The effect of repeated immersion of gypsum cast in sodium hypochlorite and glutaraldehyde on its physical properties: An in vitro study. J Pharm Bioallsci.2012;4:353-7.

5. Abdelaziz KM, Combe EC, Hodges JS. The effect of disinfectants on the properties of dental gypsum, part 2: Surface properties. Journal of Prosthodontics.2002;11:234-40.

6. Berg E, Nielson O, Skuag N.High-level microwave disinfection of dental casts. Int J Prosthodont.2005;18:520-5.

7. Kalahasti D, Hegde V, Kosaraju K, Baliga S, Reddy N. K, Sujatha BK. Evaluation of Efficacy of Microwave Irradiation in Disinfecting Dental Gypsum Casts: An Ex Vivo Study. J Indian Prosthodont Soc.2013;1-12.

8. Abass SM, Mahmood MA, Khalaf BS.Effect of microwave irradiation on disinfection, dimensional accuracy, and surface porosity of dental casts. MDJ.2011;8:177-87.

9. Hasan RH. The Effect of Microwave Disinfection on Tensile Strength of Dental Gypsum.Al-Rafidain Dent J.2008;8:213-7.

10. Silva MA,Vitti RP,Consani S.Linear dimensional change,compressive strength and detail reproduction in type IV dental stone dried at room temperature and in a microwave oven. J Appl Oral Sci.2012;588-93.

11. American National Standards. American Dental Association Specification No. 25 for Dental Gypsum Products. New York. American National Standards Institute.2000;244-53.

12. Yap Au, Yap SH, Teo JC,Tay CM,Ng KL,Thean HP.Microwave drying of high-strength stones: Effects on dimensional accuracy.Oper Dent.2003;28:193-9.

13. Pardeep K.B.Comparison of dimensional accuracy using two elastomeric impression materials in fixed prosthodontics.Pakistan Oral \& Dental Journal.2010;30:537-44.

14. Sakagushi RL,Powers JM.Craig's Restorative Dental Materials, 13th ed. London; 2012. P.300-9.

15. Leubke RJ, Chan KC. Effect of microwave oven drying on surface hardness of dental gypsum products. J Prosthet Dent.1985;54:431-5.

16. Anusavice KJ ,Shen CH, Rawls HR.Phillip's Science of Dental Materials,10th ed. Philadelphia;2013.p.182-93.

17. Robati Anaraki M, Moslehifard E, Aminifar S,Ghanati H. Effect of Microwave Disinfection on Compressive and Tensile Strengths of Dental Stones.JODDD.2013;7 